\title{
LXXI. On the crania of the Laplanders and Finlanders, with observations on the differences they present from other European races
}

James C. Prichard M.D.

To cite this article: James C. Prichard M.D. (1845) LXXI. On the crania of the Laplanders and Finlanders, with observations on the differences they present from other European races, Philosophical Magazine Series 3, 26:175, 497-502, DOI: 10.1080/14786444508645182

To link to this article: http://dx.doi.org/10.1080/14786444508645182

曲 Published online: 30 Apr 2009.

Submit your article to this journal $\pi$

Џll Article views: 1

Q View related articles $₫$ 


\section{Dr. Prichard on the Crania of the Finns and Lappes. 497}

by direct experiment; but that respecting the momentary action of heat developed amongst the molecules must, I fear, remain as a theory, to be judged of by its ability to explain a difficulty not easily surmountable otherwise. It is however, as I have already stated, manifestly a vera causa actually present, and it would not perhaps be impossible to form some rough estimate as to the probable extent of its influence.

Bath, April 19, 1845.

LXXI. On the Crania of the Laplanders and Finlanders, with observations on the differences they present firom other European races. By James C. Prichard, M.D.*

IT ITTLE has hitherto been done to elucidate the physical characters of the Ugrian or Ugorian races, under which term late writers have comprised the Finns and Lappes, the Magyars or Hungarians, and several nations of Siberia $\uparrow$.

This is owing to the fact that but few specimens of the skulls of these nations exist in any of the collections in Europe, and few and by no means perfect descriptions of them have been published. Blumenbach has given in his 'Decades Craniorum' a representation of the skull of a Lappe, and he describes it as approaching altogether to the Mongolian variety. Dr. Hueck gives an account of the appearance and general physical characters of the Esthonian Finns, and sums up his observations by pointing out some very considerable differences which he finds between them and the Mongolian form; in fact he says that he can discover nothing common to the Mongolian and Esthonian skulls, except a certain squareness of figure, which is not constant.

From these statements we should be led to suppose that there is a great difference between the skulls of the Finns and Lappes, and we should be inclined to adopt the opinion maintained by Lehrberg, that they are two separate and distinct races, his argument being founded upon the moral as well as the physical diversities between them $\$$.

On the other hand, the history of the people, and especially the great similarity of their languages, go far to prove a near relationship between the Finnish and Lappish nations; nor is a greater or less degree of civilization to be looked upon as a proof of diversity of origin, although it may be the cause of all the moral, and possibly of the physical differences also, which exist between the Finns and Lappes.

From this uncertainty it becomes much more important to ascertain, by the examination of their skulls, what the physical characteristics of each nation are, and whether they exhibit any points of

* From the Proceedings of the Zoological Society for August 13, 1844.

+ Der Ugrische Volkstamm von F. H. Müller.

† Lehrberg, über die Wolnnitte der Jemen, ein Beitrag zur Geschichte Neu-Finnlands, in Untersuchungen zur Erläiterung der alten Gesehichte Russlands.

Phil. Mag. S. 3. Vol. 26. No. 175. June 1845. 2 L 


\section{Dr. Prichard on the Crania of the Finns and Lappes.}

resemblance which may confirm the supposition that there is affinity between them, or whether, on the contrary, a sufficient degree of dissimilarity can be made out, from an accurate examination, to entitle us to set them down as separate races, and to class them with different grand divisions of the human species; whether, in short, these differences, if any such are found, are more than can be accounted for by the diversity of climate and modes of life which are well known long to have existed between them.

The examination of these skulls for the purpose of furnishing an accurate description of their appearance is interesting in another point of view. In Scandinavia and in Denmark there are numerous tumuli which contain osteological remains of former inhabitants, and it is a disputed point whether they are the remains of a Finnish aboriginal stock or of Cimbrian or some unknown race, since they differ from the old German remains. Now if we could establish a correct notion of the Finnish description of skull, we should have no diffculty in deciding whether the remains before mentioned belonged to this stock.

Having four specimens of these skulls, two of Finns and two of Laplanders, which my father has received through the kindness of Dr. Ilmoni and Mr. Daniel Wheeler, of Bristol, I have an opportunity of examining their peculiarities and of comparing them with each other and with the skulls of other Europeans, Chinese, American Iudian, and the Esquimaux, the latter of which is a most remarkable specimen of the pyramidal and broad-faced skull.

Upon taking a general view of these skulls, there are no remarkable features which strike us so forcibly as those which we see in the conformation of the Esquimaux. In fact, the only point worthy of notice here, before we commence the particular description, is a degree of general breadth in the face superior to that which is seen in the European generally, which gives to the whole an appearance of squareness when the lower jaw is attached, and causes the actual shortness of the face, which is remarkable in these skulls, to become still more apparent. The general resemblance between the Finnish skulls and those of the Lappes is as strong as between four average European crania, even belonging to the same nation, and altogether their contour decidedly approaches what Blumenbach calls the Mongolian form of skull, the head appearing, as it has been noticed by an ocular observer, ' of the shape of a pent-house.'

It will be found, however, that it is more especially in a close and minute examination that differences are seen to exist between the Lappes and Finns on the one hand, and the European skulls on the other.

Viewed from above and behind, there is a slight difference observable between the Finn and the Lappe : the posterior part of the Lappe is larger than the anterior, while the form of the Finn is more regular and rounded; that is, the line between the parietal protuberances exceeds the transverse diameter of the forehead more in the Lappe than in the Finn. I find, however, that there is equal difference in this respect between two European skulls even of the same nation. 


\section{Dr. Prichard on the Crania of the Finns and Lappes. 499}

Again, from the same point of view the skulls of the Lappes present a central eminence or ridge, upon looking at the outline of the forehead (being the line of junction of the two halves of the frontal bone), which is much less marked, in fact scarcely discernible in the Finn, and altogether absent in the European, being on the contrary very strikingly prominent in the Esquimaux. Examined anteriorly, however, a general view of these skulls gives us exactly opposite results; for the sagittal suture, which is now the median line, and the continuation backwards of the frontal suture of early life, upon looking at the outline or horizon of the skull, is seen to project decidedly more in the Finn than in the Lappe; in both more than in other Europeans. Hence we may fairly lay down, that the skulls of the Finns and Lappes have (as far only as the vault of the cranium, exclusive of any effect produced by the width of the face, allows us to conclude, more tendency to the pyramidal form than the European, hut less than the Esquimaux.

Examining these skulls anteriorly, taking into consideration the face, the triangular form is very evident, partly in consequence of the fact above mentioned respecting the vault of the cranium, and partly in consequence of the great width between the external surfaces of the malar bones, which in actual measurement in the two Lappes and the two Finns exceeds the length of the same diameter in other Europeans by at least half an inch, and in one case by nearly an inch, being equal to the same diameter in the Esquimaux; in the latter, however, which exhibits the pyramidal shape in a remarkable degree, the form is owing as much to the shape of the forehead as to the lateral projection of the anterior roots of the zygomatic processes. This width across the face is, as has been correctly observed by Dr. Hueck, not owing to the increased breadth or altered shape in the malar bone, so much as to the altered width and direction of the malar process of the superior maxillary bone.

The outline of the external surface of this bone, viewed from a point exactly in front of the skull, that is to say, the line which runs from the furthest molar tooth that is visible from this point to the suture connecting the malar and superior maxillary bones, is, in the generadity of Europenn crania, either vertical, or sometimes even inclined inwards and upwards in the first part of its course, after. wards turning outwards to form the commencement of the zygoma. In the Esquimaux this line runs obliquely upwards and outwards, at an angle of $45^{\circ}$ from its commencement; and in the skulls of the Finns and Lappes it is intermediate to the two directions, being however still inclined outwards. This obliquity is also decidedly more marked in the Finns than in the Lappes.

Upon this the anterior view, more of the lateral aspect of the lower jaw is seen than is ordinarily observed, in consequence partly of the greater distance between the condyles, which will be again noticed in the examination of the base of the skull, and partly from the fact that the angles project more in a lateral direction, the entire bone being apparently more developed than in other Europeans.

With respect to some more minute points regarding these skulls, $2 \mathrm{~L} 2$ 


\section{Dr. Prichard on the Crania of the Finns and Lappes.}

the superciliary ridges are well-marked, the ossa nasi, and the ascending processes of the superior maxillary bones present a flatter and broader anterior surface than the European, and the cavities and foramina are well-marked. [In all these four sknlls the supraorbital opening for the frontal nerve and artery is a complete foramen upon the left side, and merely a notch upon the right.]

In consequence of the greater width of the superior maxillary bone, the shape of the circumference of the orbit is not so round as in the generality of European skulls, where the external inferior angle is the lowest, but it is square, with the angles rounded; and for the same reason the space for the antrum is increased, while the depth of the infraorbital or canine fossa is very materially decreased : in one of the Finnish skulls this surface, from the inferior edge of the orbit to the alveolar processes, is almost plane. There is nothing remarkable in the nasal aperture. The shape of the orbit differs materially from that of the Esquimaux, where it is almost round, and from that in the skull of an Indian of the Sioux tribe, where it much resembles the European.

The distance from the inferior edge of the nasal aperture, that is, from the anterior nasal spine to the margin of the alveolar process, is in every specimen of these skulls of the Finns and Lappes decidedly less than in any other European with which I have compared them. The teeth are much ground.

A lateral view of these crania shows that the forehead is somewhat more receding than in the generality of Europeans, although the difference is not great, probably not more than is frequently seen between two specimens of the same tribe.

The general shape of the head resembles that of the European anteriorly, but the posterior part does not project so much. There is a marked difference between the posterior projection of the Finns and Lappes and that of the Esquimaux, the latter being much more prominent.

The line which represents the outline of the ossa nasi, \&c., i.e. the profile of the face of the skull, presents much less marked irregularities than the European in general. Thus although, as I have before observed, the superciliary ridges are well-marked, the frontal bone does not overhang the ossa nasi, as in the latter, where a decided angle is formed. In the Esquimaux the line from the forehead to the nose is nearly straight, and in the skulls of an Indian of the Sioux tribe and a Chitamache Indian the curve is very regular and open. The junction of the nose and forehead in the Lappes and Finns is therefore more angular than either of the three last-mentioned crania, but much less so than the European.

Upon this the side view another remarkable fact is observed. The occipital bone being not so much developed downwards as in other Europeans (we observed just now that it had less posterior projection also), and the posterior edge of the lower jaw, from the condyle to the angle, being longer than in the latter, upon placing the skull upon a table or any plane horizontal surface, the inferior maxilla merely touches it by its angle, not resting upon the base of the jaw, 


\section{Dr. Prichard on the Crania of the Finns and Lappes. 501}

as we observe in the English, Irish, ancient Irish (cast), Sioux, Italian and Mulatto skulls. The only ones which have this character in common with the Lappes and Finns are the Negro and the skull of a Hindu.

The angle of the lower jaw is certainly more obtuse, seen upon comparing skulls in which the molar teeth remain perfect. In the form and direction of the coronoid process there seems to be no great difference.

The temporal fossæ are well-marked, and in one of the Finnish skulls the anterior inferior angles of the parietal bones are connected to the great wings of the sphenoid by means of an os wormianum upon either side. This is not unfrequently the case in other crania.

The general shortness of the face which has been observed to exist in these skulls, is more plainly seen by viewing them from the side, when we find that the inferior edge of the malar bone is very little higher than the edge of the alveolar process. This is owing not so much to the want of development downwards of these processes, although I have already noticed the shortness of the snace between the nose and the mouth, but to the great breadth (from above downwards) of the malar bone, measured from its free inferior border to its junction with the external orbital process of the frontal bone; and it is a remarkable fact, that this measurement, in all the specimens of the skulls of Finns and Lappes, considerably exceeds that of any of the other specimens of European nations, and is equal to that of the Esquimaux and American skulls. The breadth of this surface of the malar bone in one Finn much exceeds that of any which I have had an opportunity of measuring.

Thus the shortness of the face is more apparent upon the lateral view of the cranium, in consequence of the additional width of the mular bone.

The general shape of the basis cranii presents nothing very striking, with the exception of the zygomatic arches. The foramen magnum is of a more oval form than usual, and there appears to be scarcely as great a development of the occipital bone. This agrees with what we observed when considering the lateral aspect of these skulls, and with what has previously been noticed by Dr. Hueck respecting the space for the cerebellum, which, upon an examination of the interior of the cranium, is said to be small, in consequence of the slight concavity of the inferior occipital fossa. The condyles of the occipital bone are remarkably large, being, in three out of four of these skulls, an inch in the long axis, and in one of them (the Finn) longer. They are not unusually broad. This is not the case in any other European cranium which I have examined, but is seen in the Hindu, Chitamache Indian, and to a certain extent in the Esquimaux. There must doubtless have been a much greater freedom of motion backwards and forwards in these joints than is usually the case.

The zygomatic arches, which are best seen at the base, are much more curved than in the other Europeans, slightly less so than in the Esquimaux; and the anterior projection of the alveolar processes beyond the anterior termination of the zygoma is also intermediate between the European and the Esquimaux. 
The glenoid cavities are flatter, more widely separated, and not so well-defined as in the European generally, and a difference corresponding to this is seen in the lower jaw, where the condyles, besides being more widely separated from one another, are also more rounded in form, allowing of a greater degree of lateral motion. In correspondence with this fact we also find that the pterygoid processes of the sphenoid bone, especially the external plates, are widened and enlarged, extending farther outwards, affording a greater space for the attachment of the pterygoid muscles, whose duty it is to perform the lateral or grinding motion in mastication. I mentioned above the corresponding fact of the teeth being much worn down.

The ridges for the attachment of the muscles on the palate bone are well-marked, and viewed from below it is seen that the alveolar processes do not project so much from the horizontal part of the palate; that is, that the entire hard palate presents a general curve throughout, instead of being at first plane with a sudden bend, or almost an angle, which is seen at the point where the alveolar processes are given off in the generality of European skulls.

These skulls of the Finns and Lappes are very solid and heavy.

Although this description of the Finnish skulls corresponds in very many respects with that given by Dr. Hueck, yet the examination leads us to an exactly opposite conclusion, viz. that there are very many points in common between the Finn and the races characterized by the pyramidal-shaped skull, and the conclusion with regard to the Lappe corresponds to that which was published by Professor Blumenbach. We are hence able to lay down, that there is no important difference between the skulls of the Finns and Lappes, but that, on the contrary, there is a very great resemblance between them; that altogether they are more nearly allied to the Hyperborean form than to the European ; and that if any difference does exist between them, it is that the Finns approach more nearly to this conformation of skull than the Lappes.

LXXII. On the Metamorphoses of Indigo.

Production of Organic Bases which contain Chlorine and Bromine. By Dr. August Wilhelm Hormann, Assistant in the Giessen Laboratory.

[Continued from p. 404.]

Action of the fused Hydrate of Potash on DichloriSATINE.

B. Dichloraniline (Amachlophenise).

FRDMANN has proved by direct experiment that chlorisatine cannot be converted into dichlorisatine by the further action of chlorine on this substance suspended in water. I have had frequent opportunities of convincing myself likewise of this fact. If an alcoholic solution be employed the decomposition proceeds too far, and products of oxidation are obtained, viz. chloranil, chlorophenussic acid, \&c., which no longer belong to the isatine series. 